University of South Florida

DIGITAL COMMONS

Digital Commons @ University of

@ UNIVERSITY OF SOUTH FLORIDA

South Florida

School of Geosciences Faculty and Staff

Publications

School of Geosciences

$1-27-2010$

\title{
Infrasound Observations of the 2008 Explosive Eruptions of Okmok and Kasatochi Volcanoes, Alaska
}

\author{
Kenneth M. Arnoult \\ McNutt, University of Alaska Fairbanks \\ John V. Olson \\ McNutt, University of Alaska Fairbanks \\ Curt A. Szuberla \\ McNutt, University of Alaska Fairbanks \\ Stephen R. McNutt \\ University of Alaska Fairbanks, smcnutt@usf.edu \\ Milton A. Garcés \\ University of Hawaii at Manoa
}

See next page for additional authors

Follow this and additional works at: https://digitalcommons.usf.edu/geo_facpub

\section{Scholar Commons Citation}

Arnoult, Kenneth M.; Olson, John V.; Szuberla, Curt A.; McNutt, Stephen R.; Garcés, Milton A.; Fee, David; and Hedlin, Michael A.H., "Infrasound Observations of the 2008 Explosive Eruptions of Okmok and Kasatochi Volcanoes, Alaska" (2010). School of Geosciences Faculty and Staff Publications. 324. https://digitalcommons.usf.edu/geo_facpub/324

This Article is brought to you for free and open access by the School of Geosciences at Digital Commons @ University of South Florida. It has been accepted for inclusion in School of Geosciences Faculty and Staff Publications by an authorized administrator of Digital Commons @ University of South Florida. For more information, please contact digitalcommons@usf.edu. 


\section{Authors}

Kenneth M. Arnoult, John V. Olson, Curt A. Szuberla, Stephen R. McNutt, Milton A. Garcés, David Fee, and Michael A.H. Hedlin 


\title{
Infrasound observations of the 2008 explosive eruptions of Okmok and Kasatochi volcanoes, Alaska
}

\author{
Kenneth M. Arnoult, ${ }^{1}$ John V. Olson, ${ }^{1}$ Curt A. L. Szuberla, ${ }^{1}$ Stephen R. McNutt, ${ }^{2}$ \\ Milton A. Garcés, ${ }^{3}$ David Fee, ${ }^{1,3}$ and Michael A. H. Hedlin ${ }^{4}$ \\ Received 1 February 2010; revised 5 July 2010; accepted 12 July 2010; published 29 October 2010.
}

[1] The recent explosive eruptions of Okmok and Kasatochi volcanoes provide an opportunity to use seismic, local infrasound, distant infrasound array, and remote sensing data in concert to better monitor volcanoes in the Aleutian Arc and to better understand the source processes. The eruption of Okmok Volcano began on 12 July 2008 and included a seismically active phase that lasted continuously for about $10 \mathrm{~h}$. In contrast, the eruption of Kasatochi which began on 7 August 2008 consisted of five explosive events that lasted from 26 to $68 \mathrm{~min}$ each and had a cumulative duration of $3.4 \mathrm{~h}$. Given the event times by local seismic stations, the corresponding infrasound signals were found in the data recorded by local infrasound sensors and by distant infrasound arrays. Signals from the Okmok eruption were detected by three International Monitoring System (IMS) arrays as far away as $4400 \mathrm{~km}$; signals from the Kasatochi eruption were detected at greater distances up to $5200 \mathrm{~km}$ away by seven infrasound arrays including the ones that detected the event at Okmok Volcano. Back azimuth propagation and a simple acoustic wave propagation model in unison with known event times were used to confirm that the planar, acoustic signals recorded at the arrays had originated from the eruptions. The infrasound array data reflected the differences in eruption styles between Okmok and Kasatochi as the signals from Kasatochi were of shorter duration, of greater amplitude, and detected over greater distances. The infrasound array data were also able to distinguish between two types of tremor episodes that occurred at Kasatochi Volcano based on atmospheric disturbance.

Citation: Arnoult, K. M., J. V. Olson, C. A. L. Szuberla, S. R. McNutt, M. A. Garcés, D. Fee, and M. A. H. Hedlin (2010), Infrasound observations of the 2008 explosive eruptions of Okmok and Kasatochi volcanoes, Alaska, J. Geophys. Res., 115, D00L15, doi:10.1029/2010JD013987.

\section{Introduction}

[2] Okmok, one of the most active volcanoes in Alaska's Aleutian Arc, began erupting on 12 July 2008. According to Larsen et al. [2009], less than $5 \mathrm{~h}$ of precursory seismic activity was the only indication of the eruption to follow that would last for five weeks. Within the first three hours of the eruption, the resulting plume had extended more than $100 \mathrm{~km}$ in all directions and had reached a height of $16 \mathrm{~km}$ above mean sea level. The first $10 \mathrm{~h}$ of the eruption starting at 1943 UT on 12 July 2008 was a strong and continuous

\footnotetext{
${ }^{1}$ Wilson Infrasound Observatories, Geophysical Institute, University of Alaska Fairbanks, Fairbanks, Alaska, USA.

${ }^{2}$ Alaska Volcano Observatory, Geophysical Institute, University of Alaska Fairbanks, Fairbanks, Alaska, USA.

${ }^{3}$ Infrasound Laboratory, Hawaii Institute of Geophysics and Planetology, SOEST, University of Hawaii at Manoa, Honolulu, Hawaii, USA.

${ }^{4}$ Laboratory for Atmospheric Acoustics, Institute of Geophysics and Planetary Physics, University of California, San Diego, La Jolla, California, USA.

Copyright 2010 by the American Geophysical Union. 0148-0227/10/2010JD013987
}

phase of the eruption and produced infrasound signals that will be examined in this study.

[3] On 7 and 8 August 2008, Kasatochi Volcano erupted explosively five times within a period of $15 \mathrm{~h}$. Seismometers located along the Aleutian Islands recorded earthquakes beginning in early July, which intensified on 6 and 7 August. The seismic stations also recorded explosive episodes with start times of 2201 UT on 7 August 2008, and 0150, 0435, 0712, and 1206 UT on 8 August 2008; based on seismic observations, the durations of these events were approximately $68,27,35,46$, and 26 min, respectively. Beginning with the third event and continuing intermittently for the following $17 \mathrm{~h}$, Kasatochi ejected a significant amount of ash and gases into the atmosphere (as much as $1.5 \mathrm{Tg}$ of $\mathrm{SO}_{2}$ (S. A. Carn, Stratospheric loading of $\mathrm{SO} 2, \mathrm{HCl}$ and $\mathrm{BrO}$ by the August 2008 eruption of Kasatochi Volcano, Aleutian Islands, submitted to Journal of Geophysical Research, 2010) that caused at least 40 flight cancellations and stranded many thousands of travelers (C. F. Waythomas et al., The August 7-8, 2008 eruption of Kasatochi Volcano, central Aleutian Islands, Alaska, submitted to Journal of Geophysical Research, 2010). Note that the fifth event time 


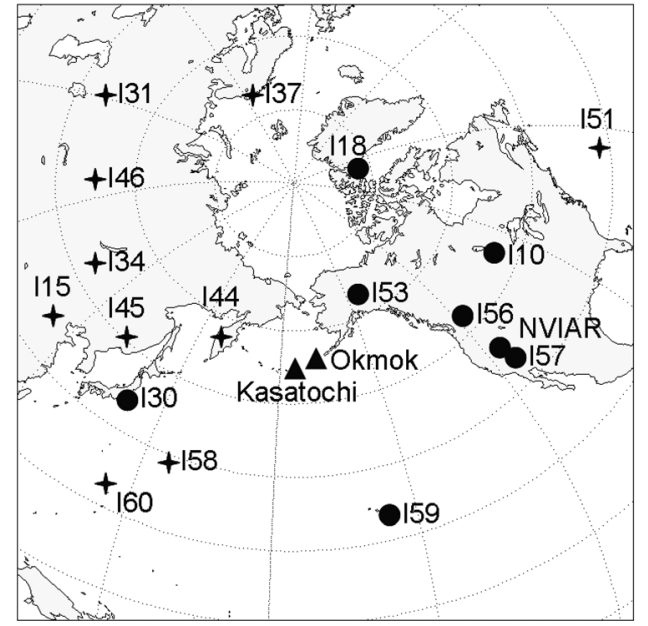

Figure 1. The seventeen IMS infrasound arrays that are located within about $10,000 \mathrm{~km}$ of the volcanic events. The sites labeled with pluses either are under construction or the data were not available to us at this time. The sites labeled with circles are the subject of this review. Kasatochi and Okmok volcanoes are indicated with triangles.

differs from that presented by Waythomas et al. (submitted manuscript, 2010) due to different selection criteria. Modeling of the Kasatochi eruptions has been performed by S. G. Prejean and E. E. Brodsky (Volcanic plume height measured by seismic waves based on a fluid dynamical model, submitted to Journal of Geophysical Research, 2010).

[4] The two eruptions provide an interesting contrast in eruption style. Although both were explosive (as compared with effusive), the initial Okmok eruption was sustained for $10 \mathrm{~h}$ whereas the Kasatochi eruption consisted of a series of brief explosions with a cumulative duration of only $3.4 \mathrm{~h}$. The Okmok eruption produced $0.3 \mathrm{~km}^{3}$ of tephra [Larsen et al., 2009] whereas Kasatochi produced about $1 \mathrm{~km}^{3}$ (C. F. Waythomas, personal communication, 2009). These firstorder observations suggest that the average mass flux at Kasatochi was nearly an order of magnitude higher than Okmok.
[5] Nearly 60 infrasound arrays comprise the International Monitoring System (IMS) infrasound network which is part of the verification regime of the Comprehensive NuclearTest-Ban Treaty (CTBT). These arrays, which monitor countries' compliance of the CTBT, each consist of four or more sensors and are approximately uniformly distributed around the world in 35 countries. Data were available from seven IMS infrasound arrays and one non-IMS array within a $6000 \mathrm{~km}$ radius of the volcanic events (Figure 1). The nonIMS array is NVIAR located near Mina, Nevada and is operated by the Southern Methodist University. The array closest to the volcanoes is I53US which is $2104 \mathrm{~km}$ from Kasatochi and $1706 \mathrm{~km}$ from Okmok.

[6] Single infrasound sensors have been placed along the Aleutian Arc by the Alaska Volcano Observatory (AVO) to monitor atmospheric disturbances associated with volcanic activity (Figure 2). Two such single sensors are located near Shishaldin and Pavlof volcanoes. Station PN7A is located $7.1 \mathrm{~km}$ west of Pavlof and uses a Chaparral Model 2.5 pressure sensor collocated with a seismic station. Data are telemetered in analog form and digitized in the UAF Seismology Laboratory at $100 \mathrm{samples} / \mathrm{s}$ with 12 bit precision. The total response is such that the sensitivity is 35 digital counts/Pa. The Shishaldin sensor (Chaparral Model 2) is located at station SSLN $6.6 \mathrm{~km}$ north of the volcano's summit, and is also collocated with a seismic station. Shishaldin is the source of as many as several hundred small explosions per day [Petersen and McNutt, 2007] so the sensitivity of the sensor is higher, 465 digital counts/Pa. Both sensors have a flat frequency response $\geq 0.1 \mathrm{~Hz}$. Station PN7A is $455 \mathrm{~km}$ from Okmok and $965 \mathrm{~km}$ from Kasatochi, while station SSLN is $313 \mathrm{~km}$ from Okmok and $817 \mathrm{~km}$ from Kasatochi.

\section{Onset and Characteristics of the Eruptions}

[7] The local Okmok seismic network consists of 13 stations at distances of 1 to $23 \mathrm{~km}$ from the active vent [Dixon et al., 2006]. Data from broadband station OKFG, $12 \mathrm{~km}$ east of the vent are shown in Figure 3. These show the onset of the eruption at 1943 UT followed by a rapid increase in amplitude $5 \mathrm{~min}$ later. Travel times from the vent to the station are only a few seconds at typical seismic velocities of $3-4 \mathrm{~km} / \mathrm{s}$ for near-surface materials. We inter-

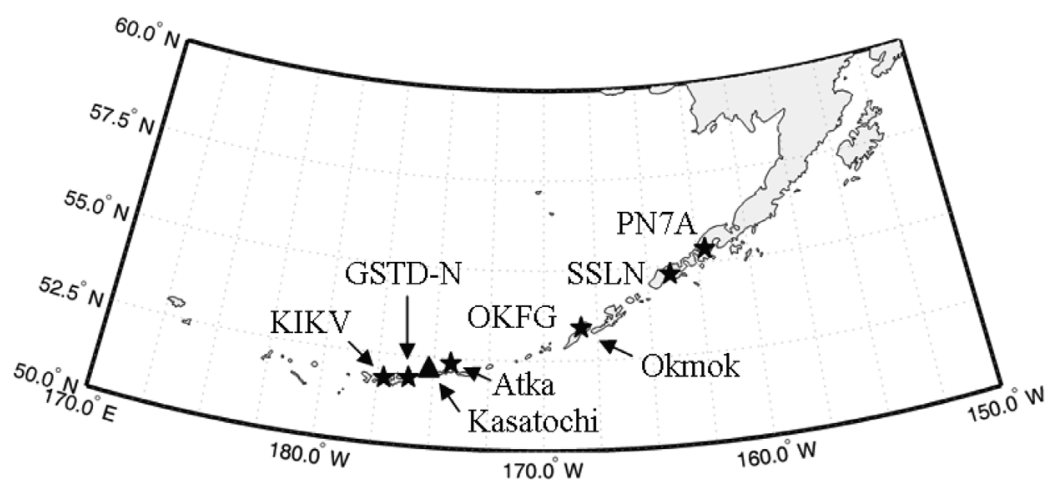

Figure 2. The seismic networks and single infrasound sensors used in this study (stars) are located on the Aleutian Islands near Kasatochi (triangle) and Okmok volcanoes. At the scale size of this map, Okmok Volcano is collocated with the seismic station at Fort Glenn (OKFG). 

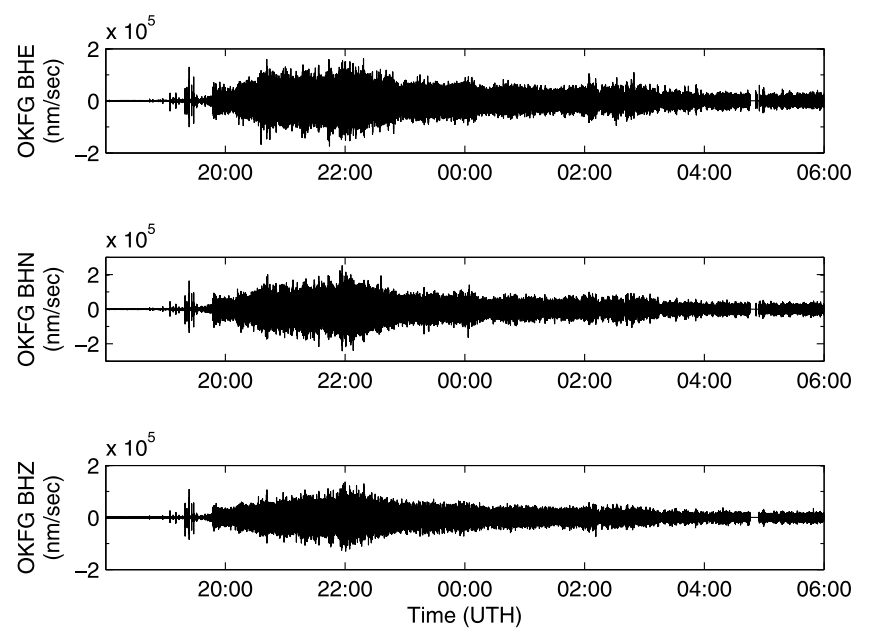

Figure 3. Three seismograms each spanning the $12 \mathrm{~h}$ from 1800 UT 12 July to 0600 UT 13 July 2008 measured ground motion in (top) the east-west direction, (middle) the northsouth direction, and (bottom) the vertical $(Z)$ direction. These seismograms were recorded by the OKFG station at Fort Glenn on the eastern flank of Okmok during the strongest phase of the Okmok eruption which began at 1943 UT but quickly escalated at 1948 UT. Earthquakes were recorded as impulses from approximately 1900 to 1940 UT just prior to the beginning of the eruption. Data gaps are present at approximately 2010, 2340, and 0450 UT.

pret the strong seismic phase at 1948 UT to be the beginning of the strong explosive phase of the eruption, and would be the expected onset of strong acoustic waves. The seismic signal and eruption increased in intensity and reached their peak about $2 \mathrm{~h}$ later at $2200 \mathrm{UT}$, followed by $8 \mathrm{~h}$ of gradually declining activity. The bulk of the coarse grained tephra and perhaps one half of all the tephra $\left(0.3 \mathrm{~km}^{3}\right.$ total $)$ were erupted in this first $10 \mathrm{~h}$ long sustained explosive phase (J. Larsen, personal communication, 2010) although additional fieldwork is needed for confirmation. We looked for the Okmok signal in infrasound and seismic data from stations SSLN and PN7A but could not identify any signal above the noise level, in spite of numerous attempts using various band pass filters.

[8] The seismic signal was quite strong and showed up on stations to distances of $257 \mathrm{~km}$. Using a common metric known as reduced displacement $\left(\mathrm{D}_{\mathrm{R}}\right)$ [Aki and Koyanagi, 1981; Fehler, 1983] which is RMS amplitude corrected for geometric spreading, we obtain values of 36 to $85 \mathrm{~cm}^{2}$ for different stations. These are fairly high values and compare with strong eruptions at Pavlof in $1986\left(54 \mathrm{~cm}^{2}\right)$ and Shishaldin in $1999\left(46 \mathrm{~cm}^{2}\right)$, each of which produced ash columns to heights of $15 \mathrm{~km}$ or more [McNutt et al., 1991; Thompson et al., 2002], similar to the Okmok eruption.

[9] A fundamental difference between Okmok and Kasatochi is that the latter was not monitored by AVO prior to the eruption. This means there were no local seismic stations on the island. Instead we needed to use stations on other networks nearby (Figure 2) to locate the earthquakes (N. A. Ruppert et al., Seismic swarm associated with the 2008 eruption of Kasatochi Volcano, Alaska: Earthquake locations and source parameters, submitted to Journal of Geophysical
Research, 2010). The Great Sitkin network (GSTD-N) consisted of six stations at distances of 35-78 km to the west of Kasatochi. A second network on Atka Island consisted of seven stations $88-101 \mathrm{~km}$ to the east. Travel times for the seismic waves are 6 to $30 \mathrm{~s}$ depending on wave type and distance to various stations. Because not all the stations were functioning continuously at the time of the eruptions, the catalog of earthquakes is not uniform. Obtaining locations required at least three Great Sitkin stations and at least one Atka station. When the eruptions began on 7 August, earthquakes were still occurring at rates of several per minute. This caused problems in identifying the eruption tremor signals because they were partially masked by the discrete earthquake signals. Nevertheless, we have determined the beginning and end times and other parameters of the explosive eruptions to the nearest minute based on examining all data from Great Sitkin, Kanaga (KIKV) and Atka stations (Table 1).

[10] In contrast to the Okmok eruption, several of the Kasatochi explosive eruptions produced signals that were easily recognizable on local infrasound stations SSLN and PN7A. Telemetry problems occurred early in the sequence so only the later data were usable (Table 1). Explosions 3, 4, and 5 at 0445,0712 , and 1206 UT, respectively, were recorded on PN7A and explosions 4 and 5 were recorded at SSLN. The acoustic data for the signals are shown in Figures 4 and 5. Assuming a constant celerity of $300 \mathrm{~m} / \mathrm{s}$, the travel time for acoustic waves to SSLN is about $45 \mathrm{~min}$ for the $817 \mathrm{~km}$ path, and 54 min for PN7A at $965 \mathrm{~km}$.

[11] The Kasatochi eruption consisted of five strong pulses. These were preceded by two strong seismic tremor episodes at 1915 and 2111 UT (Table 1). No ash clouds or infrasound signals were observed associated with these tremor episodes. The first explosion at 2201 UT initially appeared to be a third tremor episode, however it produced a steam and ash cloud and infrasound signal. It was the longest explosive event at $68 \mathrm{~min}$ and had moderate seismic amplitude and moderate infrasound pressure at I53 (Table 1). The eruptive cloud was light colored in satellite images and appears to have been mostly gas (Waythomas et al., submitted manuscript, 2010). The second event at 0150 UT was short at $27 \mathrm{~min}$ and had the same seismic amplitude as event 1 , but stronger infrasound. Satellite data showed an initial black puff (ash) then white cloud (gas). The third event had a duration of $35 \mathrm{~min}$, the highest seismic amplitude (75 percent higher than events 1 or 2) and the second highest infrasound pressure. The dark ash cloud emitted appears to have been the largest and most ash-rich cloud of the sequence. The fourth and fifth events had smaller seismic amplitudes, smaller infrasound pressures, and smaller ash clouds than events $1-3$ (Table 1 ). The cumulative seismic duration for the five pulses is $3 \mathrm{~h} 22 \mathrm{~min}$.

\section{Array Detection of Kasatochi and Okmok Infrasound Signals}

[12] Before attempting to detect volcanic signals in the infrasound data, the data must first be filtered to reduce noise and contributions of signals from other sources that are not of interest. The time series recorded at all eight infrasound arrays were first band-pass filtered from 0.015 to $1.000 \mathrm{~Hz}$ then Pure-State filtered [Olson, 2004]. Displayed 

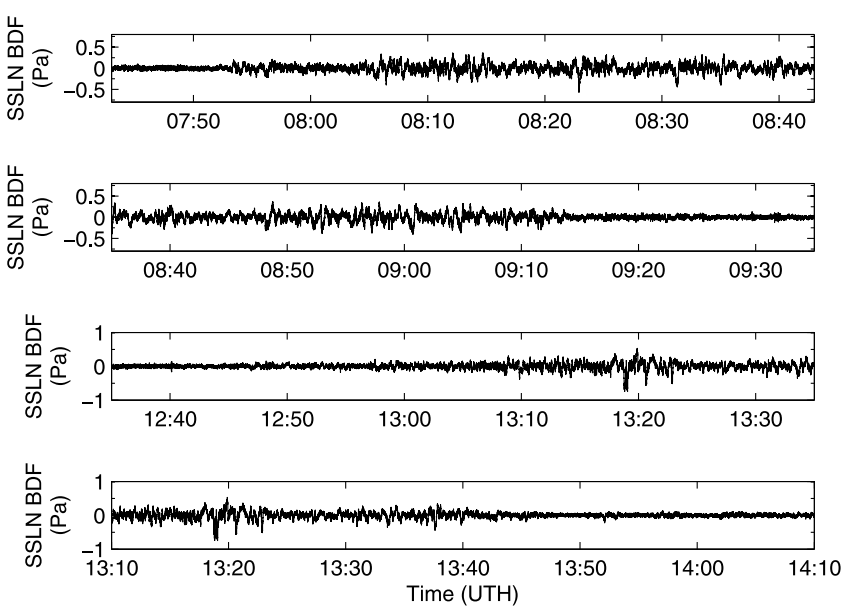

Figure 4. Unfiltered time series recorded on 8 August 2008 by a single infrasound sensor located on Shishaldin Volcano approximately $817 \mathrm{~km} \mathrm{NE}$ of Kasatochi. The fourth explosive eruption of Kasatochi, which occurred at 0712 UT, arrived at approximately 0752 UT and can be seen in the first two panels which range from (first panel) 0743 to 0843 UT and (second panel) 0835 to 0935 UT. The fifth explosive eruption of Kasatochi, which occurred at 1206 UT, arrived at approximately 1246 UT and can be seen in the last two panels which range from (third panel) 1235 to 1335 UT and (fourth panel) 1310 to 1410 UT.

in Figure 6 (top) is the time series containing signals from Okmok that was recorded on 12 and 13 July 2008 by one sensor, H1, of the I53 array. At a distance of $1706 \mathrm{~km}$ from Okmok, I53 is the closest of the eight infrasound arrays considered in this study. Shown in Figure 6 (middle and
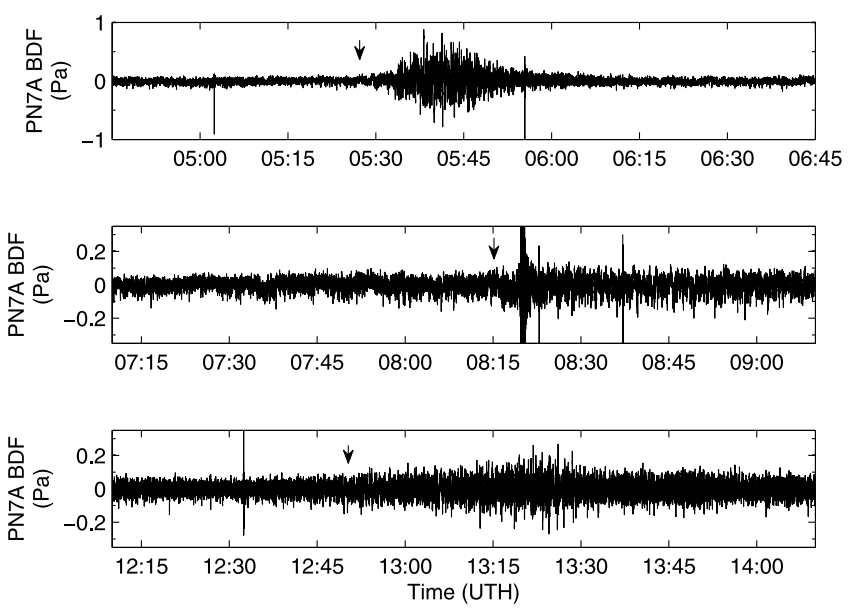

Figure 5. Time series recorded on 8 August 2008 by an infrasound sensor at station PN7A and low-pass filtered at $1 \mathrm{~Hz}$. Station PN7A is located on the northern flank of Pavlof Volcano approximately $965 \mathrm{~km} \mathrm{NE}$ of Kasatochi. Plotted are three $2 \mathrm{~h}$ segments starting at (top) 0445, (middle) 0710, and (bottom) 1210 UT are plotted at the same scale. Signals produced by the explosive eruptions of Kasatochi are visible starting at approximately 0527,0815 , and 1250 UT (arrows). The vertical lines in the time series are results of electronic drop outs. 

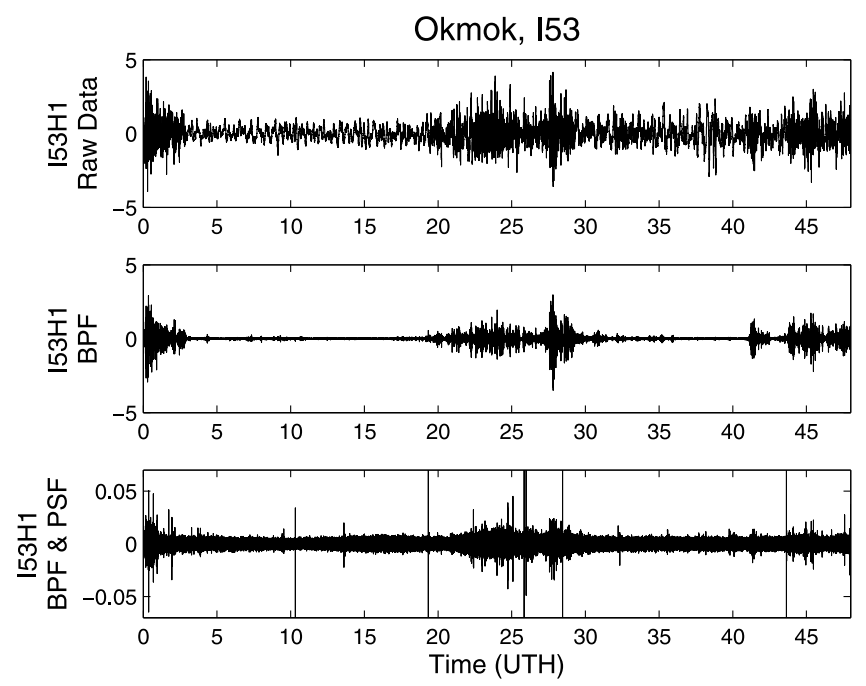

Figure 6. (top) The time series recorded by I53 on 12 and 13 July 2008 were (middle) band-pass filtered from 0.015 to $1.000 \mathrm{~Hz}$ and then (bottom) Pure-State filtered [Olson, 2004]. Results are shown for sensor H1.

bottom) is the time series after only band-pass filtering from 0.015 to $1.000 \mathrm{~Hz}$ (Figure 6, middle) and the time series after both band-pass filtering and Pure-State filtering (Figure 6, bottom). Figure 7 shows the power spectral density plots corresponding to the three time series presented in Figure 6. Note that the Pure-State Filter suppresses the power at frequencies where noise is the primary signal while leaving the power levels at those frequencies that correspond to greater generalized coherence (near $0.1 \mathrm{~Hz}$ ) virtually untouched. The Pure-State Filter can be applied to data recorded by an array of sensors but not to data from a single sensor because the filter operates by identifying generalized coherence present among multiple time series. Displayed in Figure 8 (top) is the time series containing

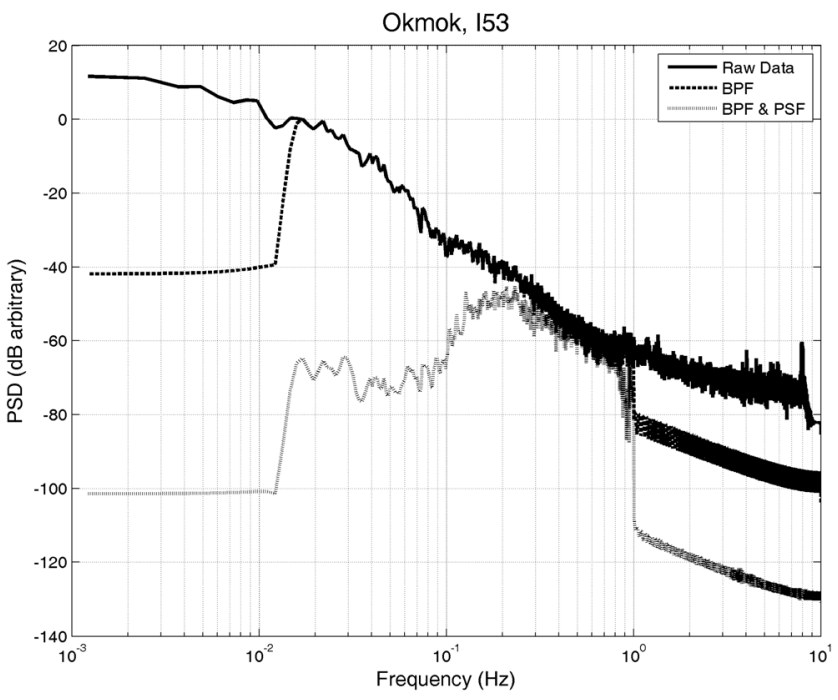

Figure 7. Power spectral density plots for the Okmok signal recorded by sensor H1 of I53 before filtering (solid line), after band-pass filtering (0.015-1 Hz, dashed line), and after BPF and Pure-State filtering (dotted line) [Olson, 2004].
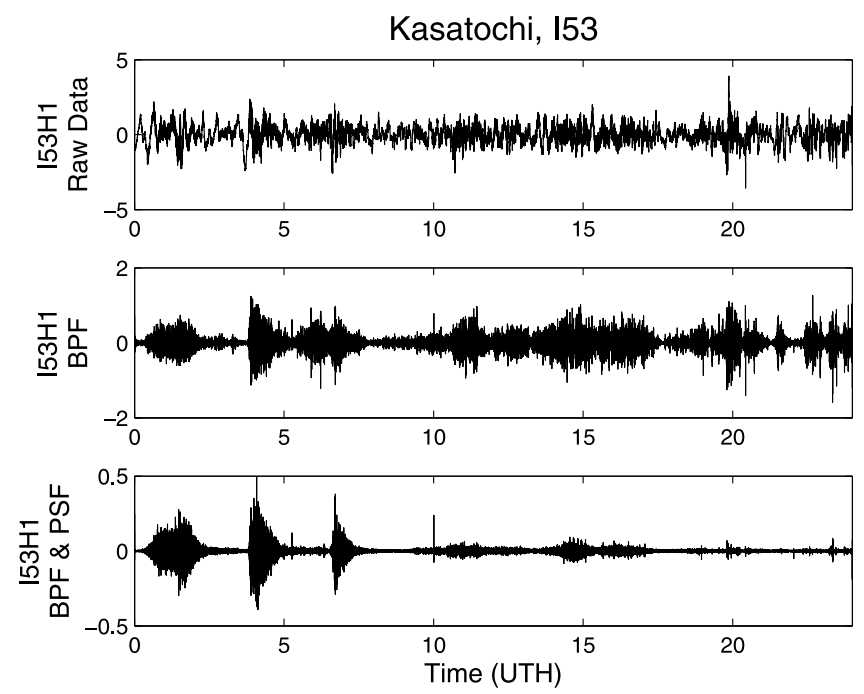

Figure 8. (top) The time series recorded by I53 on 8 August 2008 were (middle) band-pass filtered from 0.015 to $1 \mathrm{~Hz}$ and then (bottom) Pure-State filtered [Olson, 2004]. Results are shown for sensor H1.

signals from Kasatochi that was recorded on 8 August 2008 by one sensor, $\mathrm{H} 1$, of the I53 array. At a distance of $2104 \mathrm{~km}$ from Kasatochi, I53 is the closest of the eight infrasound arrays considered in this study. Also displayed in the Figure 8 are the time series after only band-pass filtering from 0.015 to $1.000 \mathrm{~Hz}$ (Figure 8, middle) and after both band-pass filtering and Pure-State filtering (Figure 8, bottom). Figure 9 shows the power spectral density plots corresponding to the three time series presented in Figure 8.

[13] A windowing technique was applied to the filtered data to detect signals. This technique consisted of stepping a $500 \mathrm{~s}$ window through the filtered time series in $50 \mathrm{~s}$ iterations. For each iteration, the data within the window

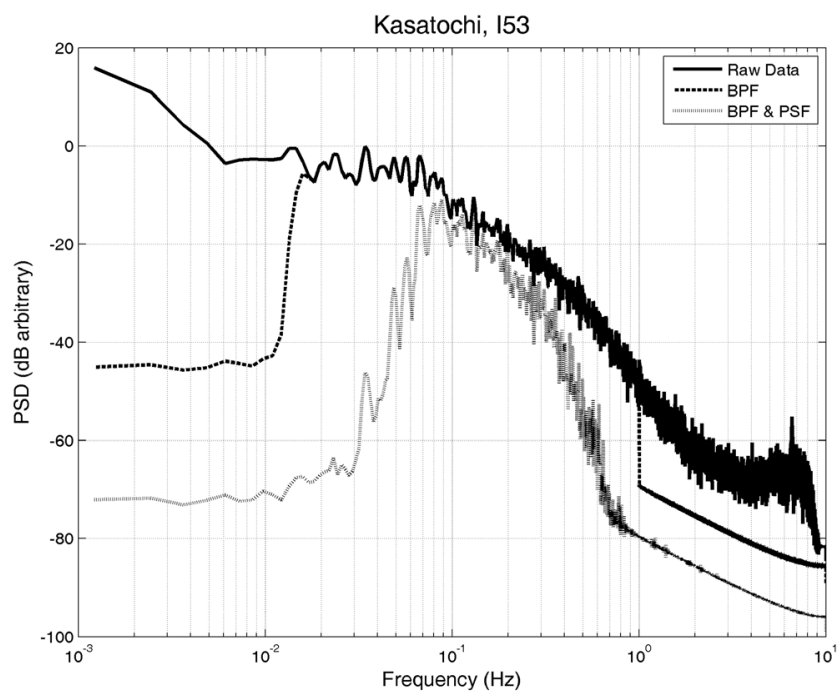

Figure 9. Power spectral density plots for the Kasatochi signal recorded by sensor $\mathrm{H} 1$ of $\mathrm{I} 53$ before filtering (solid line), after band-pass filtering $(0.015-1 \mathrm{~Hz}$, dashed line), and after BPF and Pure-State filtering (dotted line) [Olson, 2004]. 

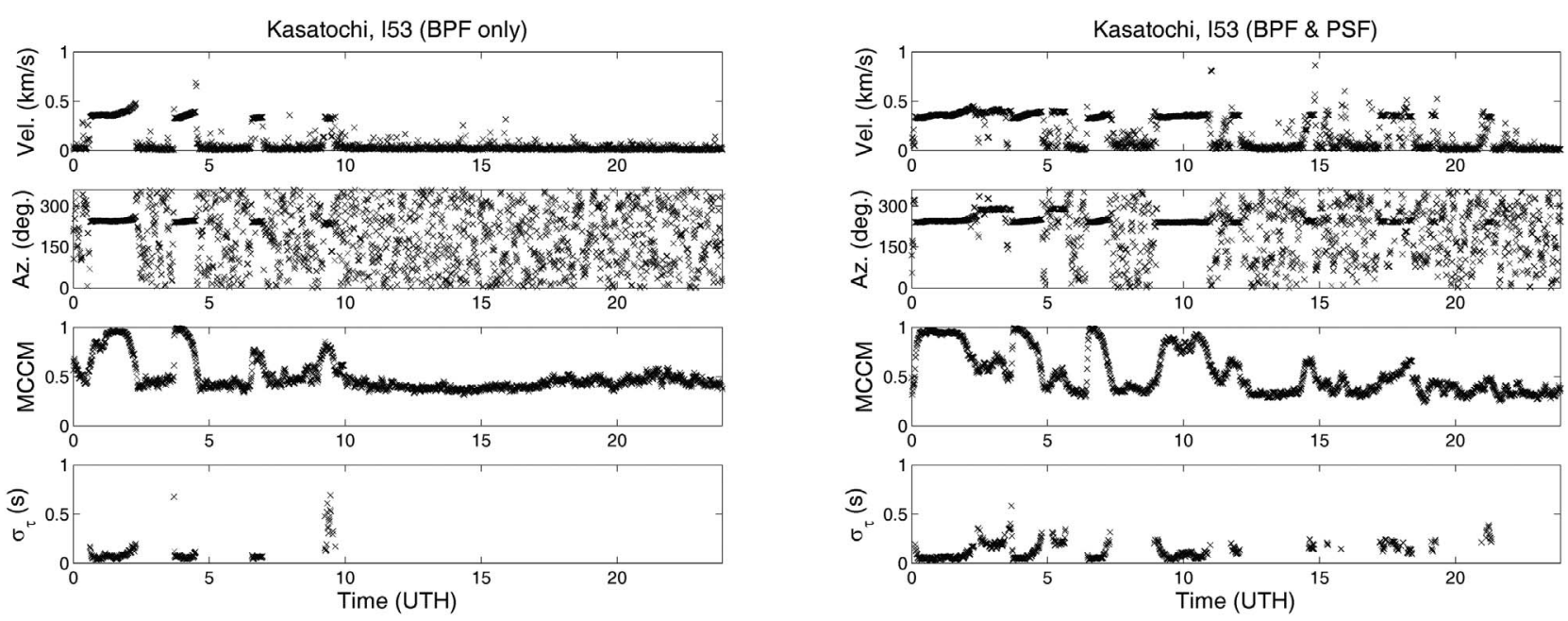

Figure 10. A comparison between (left) only band-pass filtering and (right) band-pass filtering followed by Pure-State filtering. The data recorded at I53 containing the Kasatochi signals were subjected to two different filtering processes. The first process consisted of only band-pass filtering the data; the second process consisted of band-pass filtering followed by Pure-State filtering. A windowing technique, which consisted of stepping a $500 \mathrm{~s}$ window through the data in $50 \mathrm{~s}$ iterations, was then applied to both sets of filtered data. For each iteration, estimates of (from top to bottom) trace velocity, azimuth of arrival, coherence, and planarity were computed from a least squares fit assuming plane wave arrivals. The filtering process consisting of band-pass filtering followed by Pure-State filtering was used in the study due its higher probability of detection.

was used to estimate trace velocity, azimuth of arrival (measured clockwise from north), coherence, and planarity. These estimates were computed from a least squares fit assuming plane wave arrivals [Szuberla and Olson, 2004]. Coherence can be used as a detector to determine if a signal was recorded in the data. Once a signal has been detected, trace velocity, azimuth of arrival, and planarity can be useful in distinguishing signals of interest from signals originating from other sources.

[14] After applying the widowing technique to the I53 data that was only band-pass filtered and to the I53 data that was both band-pass filtered and Pure-State filtered, it was discovered that the latter data set led to a higher probability of detection. For this reason, data recorded by the other seven infrasound arrays were first band-pass filtered and then Pure-State filtered before applying any detection techniques. For comparison, Figure 10 displays the results of the detection algorithm applied to the I53 data from 8 August 2008 after only band-pass filtering (Figure 10, left) and after both band-pass filtering and Pure-State filtering (Figure 10, right). Plotted from top to bottom are the resulting estimates of trace velocity, azimuth of arrival, coherence (mean of the cross-correlation maxima, MCCM), and planarity. Sigma-tau $\left(\sigma_{\tau}\right)$ is a metric related to the difference between the measured times of arrival and the times of arrival for a plane wave; an ideal plane wave that propagates through an array at any velocity would have a sigma-tau value of zero. For the purposes of this paper, sigma-tau values less than $1 \mathrm{~s}$ indicate planar arrivals. Notice that although both sets of filtered data led to detections of Kasatochi signals, the latter data set led to detections with greater coherence and longer detection durations. This is perhaps most noticeable in the detection of the signal that

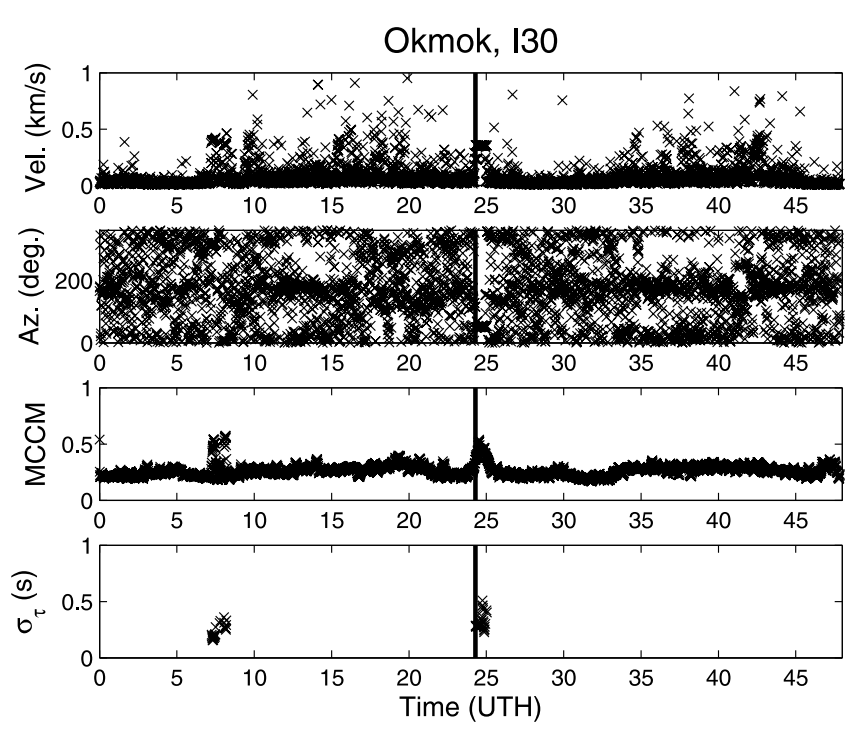

Figure 11. To detect signals, a $500 \mathrm{~s}$ window was stepped through the data in $50 \mathrm{~s}$ iterations. For each iteration, estimates of (from top to bottom) trace velocity, azimuth of arrival, coherence, and planarity were computed from a least squares fit assuming plane wave arrivals. The windowing technique was applied to the I30 time series after band-pass filtering $(0.015-1 \mathrm{~Hz})$ followed by Pure-State filtering. The vertical line in all panels indicates the estimated time of arrival of the Okmok signal based on known event times and estimated propagation times resulting from a wave propagation model. 


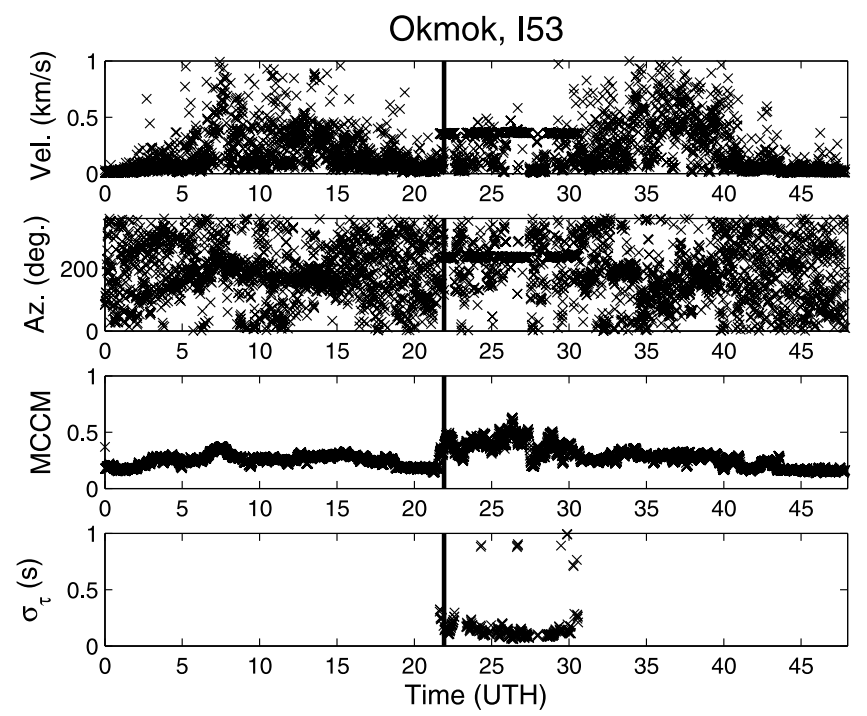

Figure 12. To detect signals, a $500 \mathrm{~s}$ window was stepped through the data in $50 \mathrm{~s}$ iterations. For each iteration, estimates of (from top to bottom) trace velocity, azimuth of arrival, coherence, and planarity were computed from a least squares fit assuming plane wave arrivals. The windowing technique was applied to the I53 time series after band-pass filtering $(0.015-1 \mathrm{~Hz})$ followed by Pure-State filtering. The vertical line in all panels indicates the estimated time of arrival of the Okmok signal based on known event times and estimated propagation times resulting from a wave propagation model.

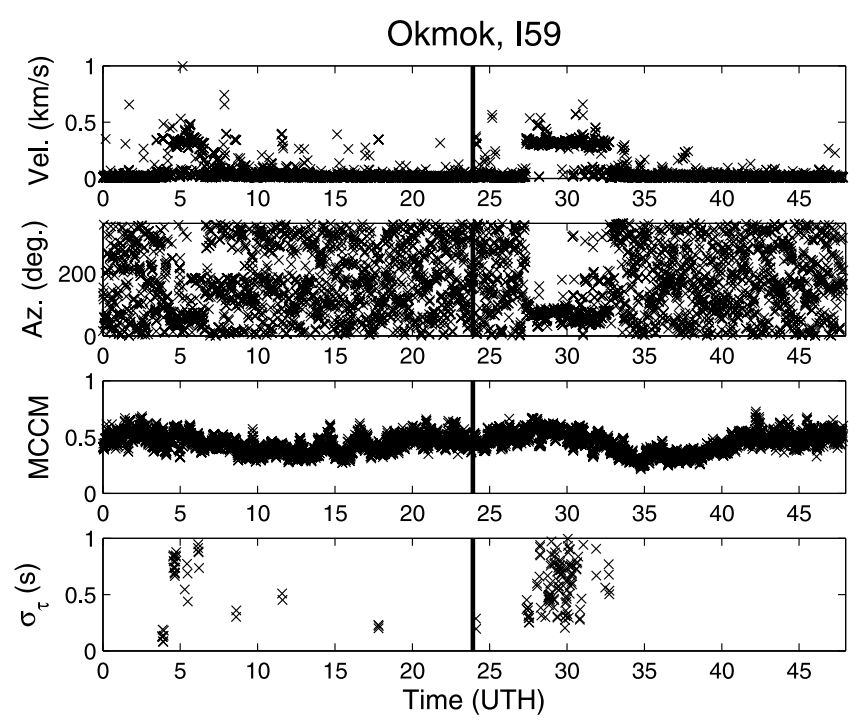

Figure 13. To detect signals, a $500 \mathrm{~s}$ window was stepped through the data in $50 \mathrm{~s}$ iterations. For each iteration, estimates of (from top to bottom) trace velocity, azimuth of arrival, coherence, and planarity were computed from a least squares fit assuming plane wave arrivals. The windowing technique was applied to the I59 time series after band-pass filtering $(0.015-1 \mathrm{~Hz})$ followed by Pure-State filtering. The vertical line in all panels indicates the estimated time of arrival of the Okmok signal based on known event times and estimated propagation times resulting from a wave propagation model.

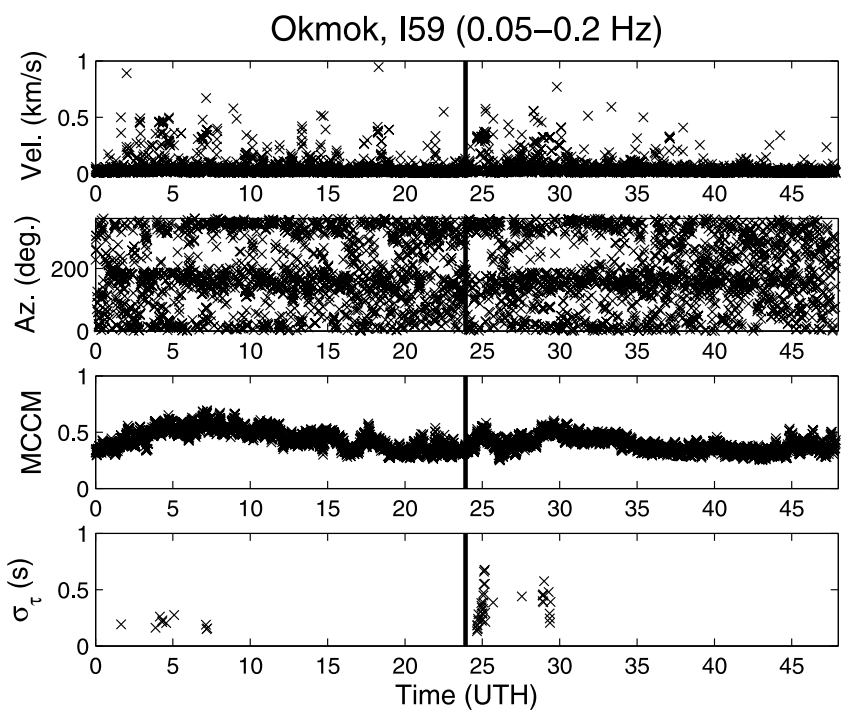

Figure 14. Though no signals from Okmok were detected initially in the I59 data that had been band-pass filtering from 0.015 to $1 \mathrm{~Hz}$ (see Figure 13), a signal was detected in the I59 data by instead band-pass filtering from 0.05 to $0.2 \mathrm{~Hz}$. After band-pass filtering, the data were Pure-State filtered and a windowing technique was applied that resulted in estimates of (from top to bottom) trace velocity, azimuth of arrival, coherence, and planarity. The vertical line in all panels indicates the estimated time of arrival of the Okmok signal based on known event times and estimated propagation times resulting from a wave propagation model.

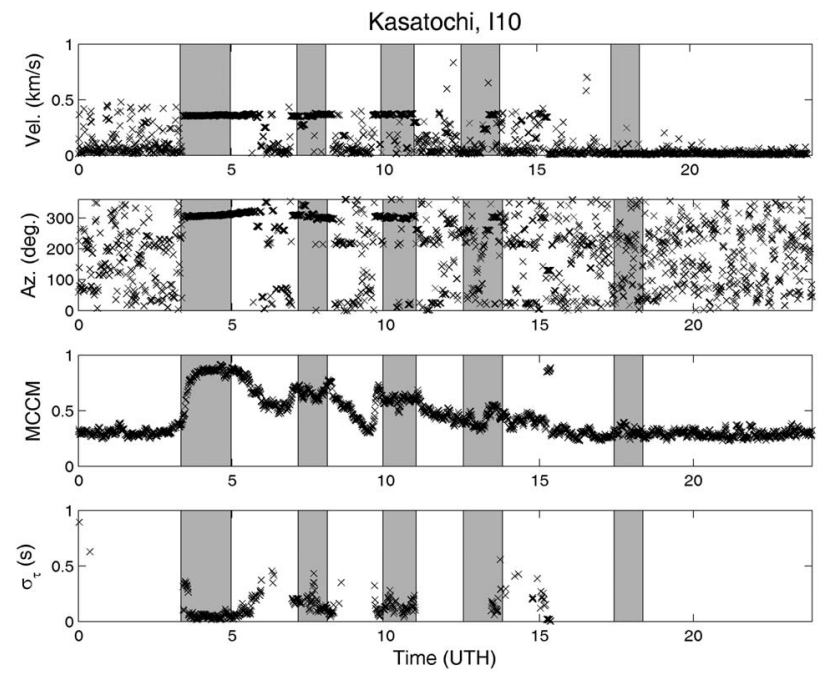

Figure 15. To detect signals, a $500 \mathrm{~s}$ window was stepped through the $\mathrm{I} 10$ data in $50 \mathrm{~s}$ iterations. For each iteration, estimates of (from top to bottom) trace velocity, azimuth of arrival, coherence, and planarity were computed from a least squares fit assuming plane wave arrivals. The windowing technique was applied to the I10 time series after band-pass filtering $(0.015-1 \mathrm{~Hz})$ followed by Pure-State filtering. The gray regions in all panels indicate the time intervals over which the Kasatochi signals are estimated to be detected at I10 based on known event times, known event durations, and estimated propagation times resulting from a wave propagation model. 

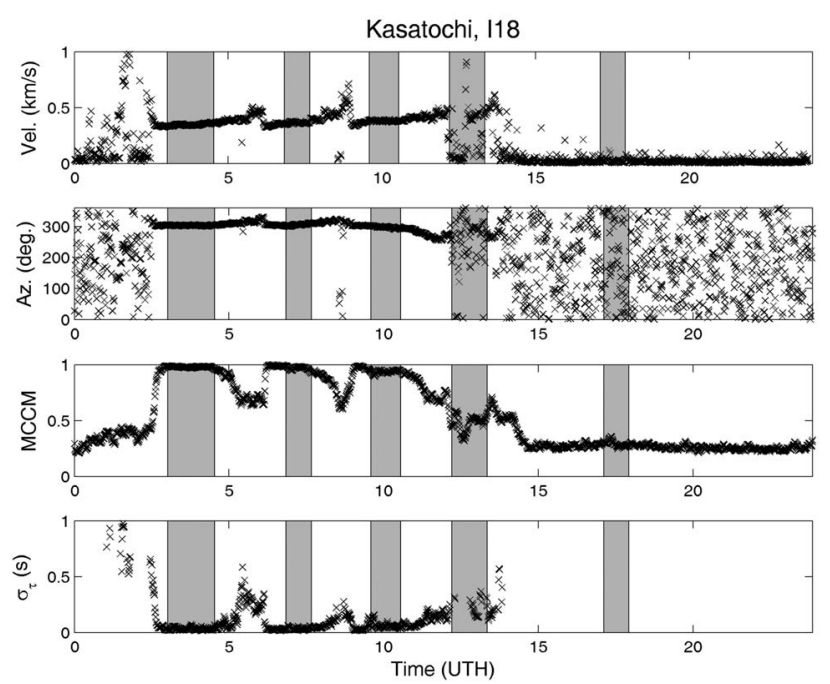

Figure 16. To detect signals, a $500 \mathrm{~s}$ window was stepped through the I18 data in $50 \mathrm{~s}$ iterations. For each iteration, estimates of (from top to bottom) trace velocity, azimuth of arrival, coherence, and planarity were computed from a least squares fit assuming plane wave arrivals. The windowing technique was applied to the I18 time series after band-pass filtering $(0.015-1 \mathrm{~Hz})$ followed by Pure-State filtering. The gray regions in all panels indicate the time intervals over which the Kasatochi signals are estimated to be detected at I18 based on known event times, known event durations, and estimated propagation times resulting from a wave propagation model.

arrived shortly after 0900 UT. Not only is its coherence greater as seen by an average increase of 0.28 in its MCCM value, but its temporal duration of detection increased from approximately 10 to $108 \mathrm{~min}$ resulting in a longer time period of consistent values in velocity, azimuth, and planarity. Also, more acoustic signals were detected in the data that had been band-pass filtered and Pure-State filtered. For example, signals which appear to be from the Kasatochi events were detected at approximately $1155,1440,1515$, 1750,1910 , and 2110 UTC that were not detected in the data that were only band-pass filtered. Other signals propagating at acoustic velocities but arriving from more northern azimuths than the Kasatochi signals were detected near 0300 and 0525 UTC.

[15] After band-pass and Pure-State filtering, the same detection technique was applied to the data from all eight infrasound arrays recorded on the days during the Okmok and Kasatochi eruptions (Figures 11-22). Signals from the Okmok eruption were detected at I30, I53, I59 (Figures 11, 12 , and 14), but not at I10, I18, I56, I57, or NVIAR. An Okmok signal was detected in the I59 data using the more narrow frequency band ranging from 0.05 to $0.20 \mathrm{~Hz}$ (Figure 14), but not using the original band ranging from 0.015 to $1.000 \mathrm{~Hz}$ (Figure 13). The signals detected at I30, I53, and I59 have trace velocities consistent with acoustic waves, azimuths of arrival roughly consistent with those expected based upon great circle paths from Okmok Volcano to the arrays (Table 2), times of arrival consistent with the event time and propagation times estimated using a simple windless atmospheric model (discussed later), and
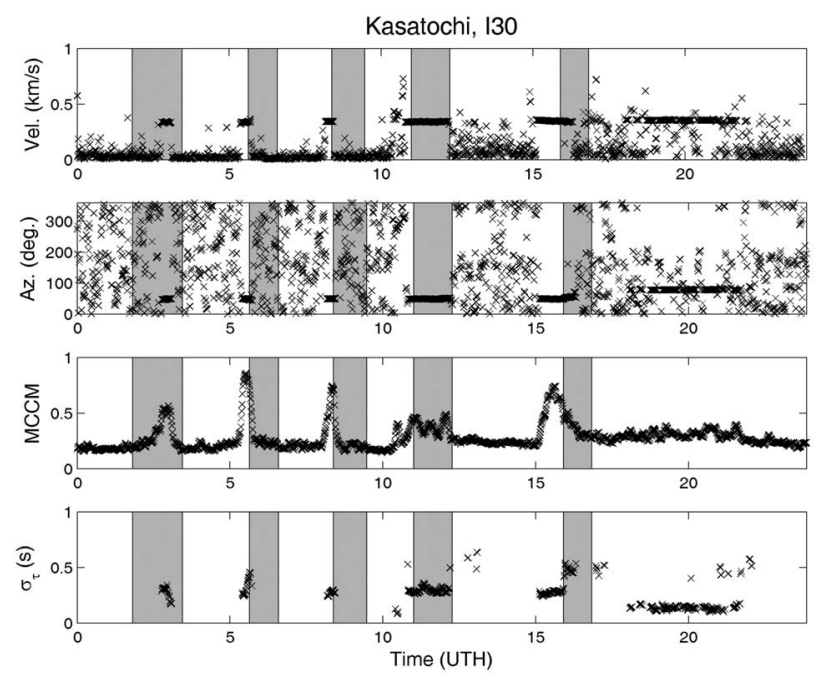

Figure 17. To detect signals, a $500 \mathrm{~s}$ window was stepped through the I30 data in $50 \mathrm{~s}$ iterations. For each iteration, estimates of (from top to bottom) trace velocity, azimuth of arrival, coherence, and planarity were computed from a least squares fit assuming plane wave arrivals. The windowing technique was applied to the I30 time series after band-pass filtering $(0.015-1 \mathrm{~Hz})$ followed by Pure-State filtering. The gray regions in all panels indicate the time intervals over which the Kasatochi signals are estimated to be detected at I30 based on known event times, known event durations, and estimated propagation times resulting from a wave propagation model.
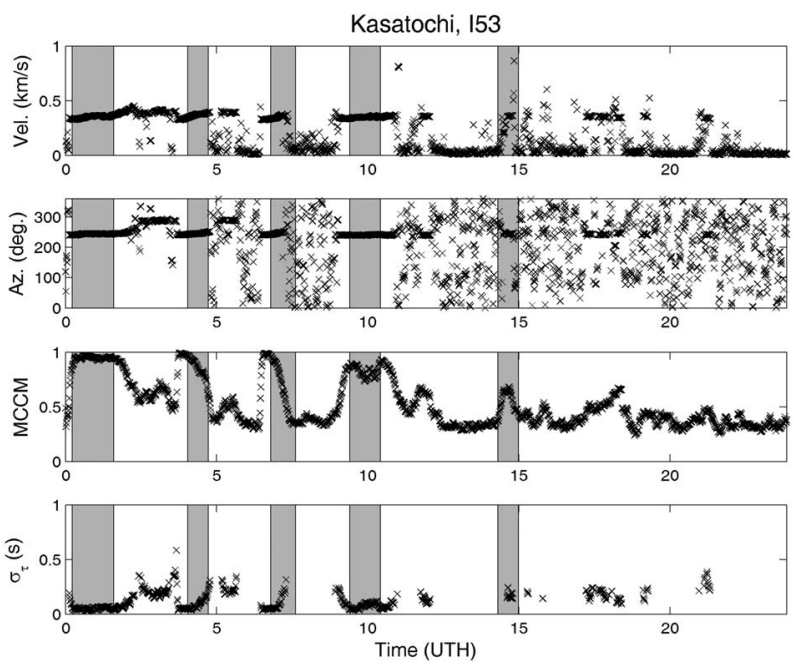

Figure 18. To detect signals, a $500 \mathrm{~s}$ window was stepped through the I53 data in $50 \mathrm{~s}$ iterations. For each iteration, estimates of (from top to bottom) trace velocity, azimuth of arrival, coherence, and planarity were computed from a least squares fit assuming plane wave arrivals. The windowing technique was applied to the I53 time series after band-pass filtering $(0.015-1 \mathrm{~Hz})$ followed by Pure-State filtering. The gray regions in all panels indicate the time intervals over which the Kasatochi signals are estimated to be detected at I53 based on known event times, known event durations, and estimated propagation times resulting from a wave propagation model. 

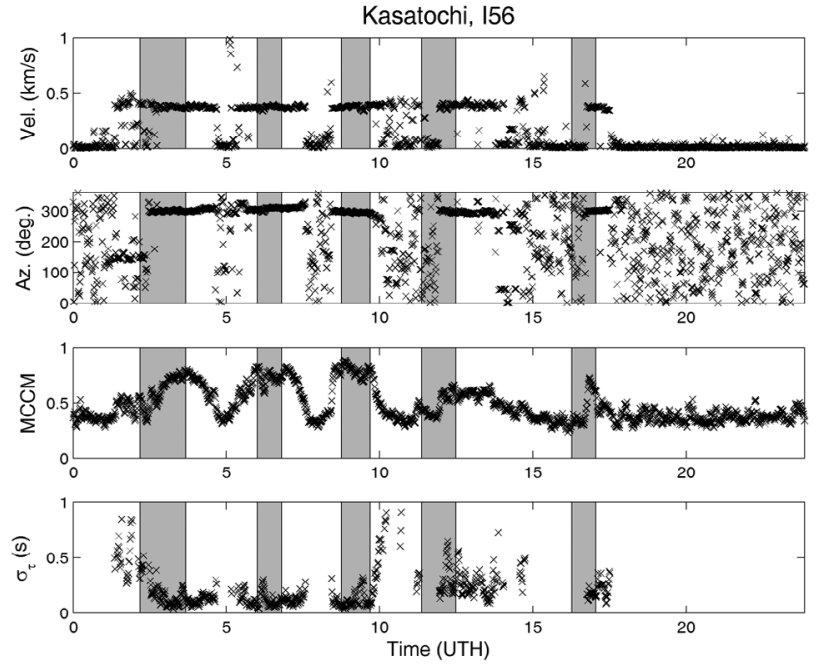

Figure 19. To detect signals, a $500 \mathrm{~s}$ window was stepped through the I56 data in $50 \mathrm{~s}$ iterations. For each iteration, estimates of (from top to bottom) trace velocity, azimuth of arrival, coherence, and planarity were computed from a least squares fit assuming plane wave arrivals. The windowing technique was applied to the I56 time series after band-pass filtering $(0.015-1 \mathrm{~Hz})$ followed by Pure-State filtering. The gray regions in all panels indicate the time intervals over which the Kasatochi signals are estimated to be detected at I56 based on known event times, known event durations, and estimated propagation times resulting from a wave propagation model.

low sigma-tau values $(<1)$ consistent with planar arrivals. Signals originating from the explosive eruptions of Kasatochi were detected at all arrays except I57. Arrays I30, I53, I56, and I59 detected signals from all five major explosive eruptions (Figures 17-19 and 21) while I10 and I18 detected signals from the first four, but not the fifth (Figures 15 and 16), and NVIAR detected the third, but not the other four (Figure 22). All of the Kasatochi signals detected by the arrays had trace velocities consistent with acoustic waves, azimuths of arrival roughly consistent with those expected based upon great circle paths from Kasatochi Volcano to the arrays (Table 3), times of arrival consistent with event times and propagation times estimated using a simple windless atmospheric model (discussed later), and low sigma-tau values $(<1)$ consistent with planar arrivals.

\section{Back Azimuth Location}

[16] Using the azimuths of arrival measured at the infrasound arrays, back azimuth projections along the great circle paths from the infrasound arrays were calculated. For Okmok, the resulting average location was approximately $500 \mathrm{~km}$ west of the volcano, and the intersections of the projections were spread over a region approximately $450 \mathrm{~km}$ wide (Figure 23). Listed in Table 2 are the azimuths measured at each array alongside the azimuths that were expected based on great circle paths from the arrays to Okmok. For Kasatochi, which had substantially stronger signals, the resulting average location was approximately $200 \mathrm{~km}$ west of Kasatochi, and the intersections of these projections were also spread over a region several hundred kilometers wide (Figure 24). Listed in Table 3 are the azimuths measured at each array alongside the azimuths that were expected based on great circle paths from the arrays to Kasatochi.

\section{Estimation of Signal Propagation Times}

[17] In order to estimate times of signal arrivals at each of the stations, a simple ray-tracing routine was developed. Assuming windless conditions and using temperature profiles of the atmosphere provided by the NRL-G2S Atmospheric Data System [Drob et al., 2003], rays were traced from the summit of each volcano to the receiving arrays. For rays that connected the two sites (Tables 4 and 5), the propagation times were estimated and used to indicate search windows for signal arrivals in the data recorded by each array. The temperature profile was updated every $1 \mathrm{~km}$ along the great circle path from the source to each infrasound array to account for spatial changes in the atmosphere's temperature profile. This windless propagation model is merely intended to provide a "first-order approximation" of signal propagation times in order to validate the detections at the infrasound arrays. For a more thorough study of the wave propagation associated with the atmospheric disturbances caused by the Okmok and Kasatochi events, see Fee et al. [2010].

[18] Only the times of arrival were estimated for the Okmok signals because the Okmok event lasted for approx-
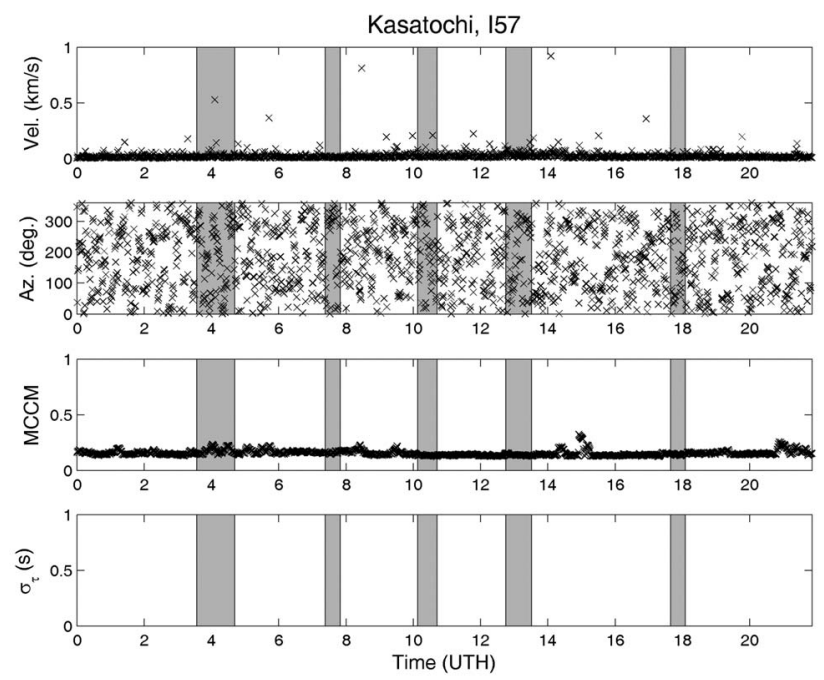

Figure 20. To detect signals, a $500 \mathrm{~s}$ window was stepped through the I57 data in $50 \mathrm{~s}$ iterations. For each iteration, estimates of (from top to bottom) trace velocity, azimuth of arrival, coherence, and planarity were computed from a least squares fit assuming plane wave arrivals. The windowing technique was applied to the I57 time series after band-pass filtering $(0.015-1 \mathrm{~Hz})$ followed by Pure-State filtering. The gray regions in all panels indicate the time intervals over which the Kasatochi signals are estimated to be detected at 157 based on known event times, known event durations, and estimated propagation times resulting from a wave propagation model. This figure serves as an example of a nondetection in contrast to Figures 15-19, 21, and 22. 

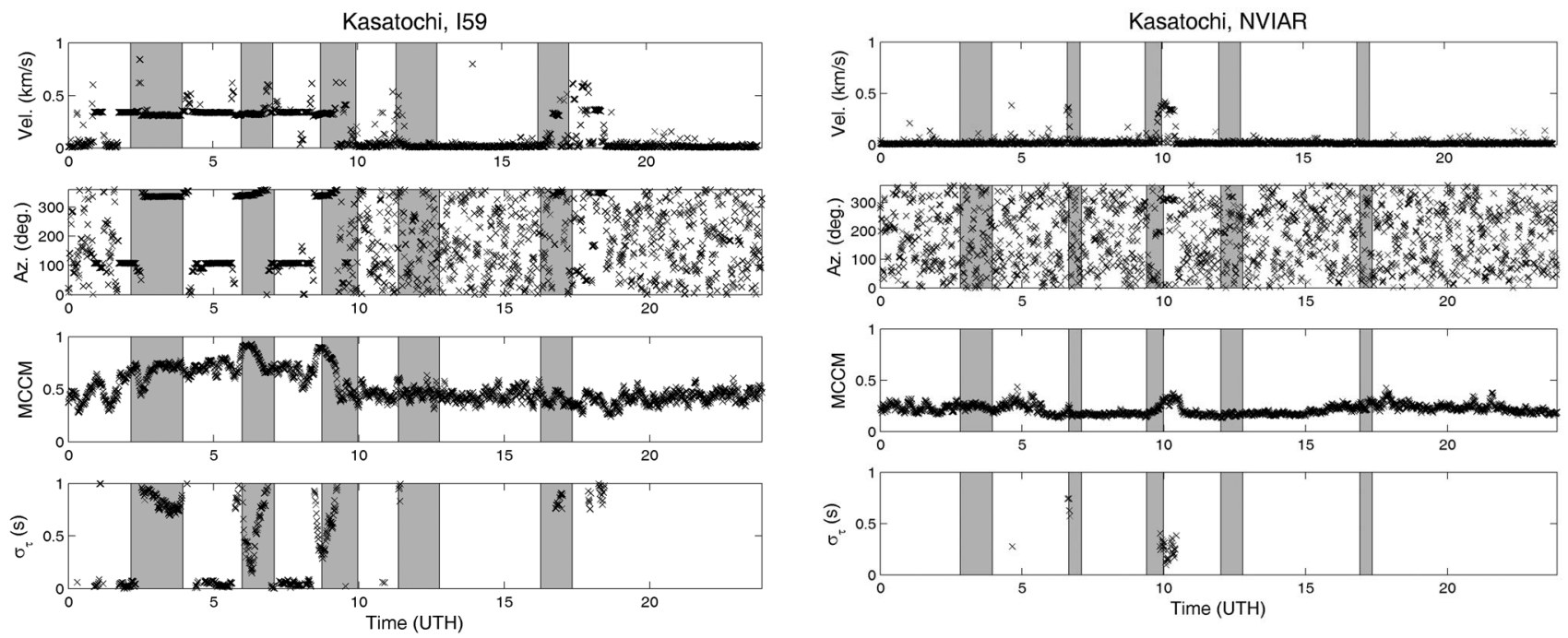

Figure 21. To detect signals, a $500 \mathrm{~s}$ window was stepped through the I59 data in $50 \mathrm{~s}$ iterations. For each iteration, estimates of (from top to bottom) trace velocity, azimuth of arrival, coherence, and planarity were computed from a least squares fit assuming plane wave arrivals. The windowing technique was applied to the I59 time series after band-pass filtering $(0.015-1 \mathrm{~Hz})$ followed by Pure-State filtering. The gray regions in all panels indicate the time intervals over which the Kasatochi signals are estimated to be detected at I59 based on known event times, known event durations, and estimated propagation times resulting from a wave propagation model.

imately $10 \mathrm{~h}$ and waned during the final hours without a clearly defined end. These estimated arrival times are depicted in Figures 11-14 as a vertical line in each panel. In contrast, the Kasatochi events had better defined start and end times. For the Kasatochi signals, time intervals in which the signals were expected to be detected were estimated using the estimated propagation times, the known event times, and the known event durations. These estimated time ranges are highlighted in each panel of Figures $15-22$ by semitransparent gray rectangles.

\section{Discussion}

[19] Infrasound signals from the most recent explosive eruptions of Okmok and Kasatochi were detected by single infrasound sensors located along the Aleutian Arc and also

Table 2. Great Circle Path Distances and Azimuths and Measured Azimuths to Okmok From Each Infrasound Array Sorted by Distance

\begin{tabular}{lccc}
\hline Array Name & $\begin{array}{c}\text { Distance to } \\
\text { Okmok }(\mathrm{km})\end{array}$ & $\begin{array}{c}\text { Azimuth to } \\
\text { Okmok (deg) }\end{array}$ & $\begin{array}{c}\text { Measured Azimuth } \\
\text { to Okmok (deg) }\end{array}$ \\
\hline I53 & 1706 & 231.4 & 242.8 \\
I56 & 3548 & 298.8 & N/A \\
I59 & 3903 & 347.3 & 340.4 \\
NVIAR & 4097 & 310.6 & N/A \\
I30 & 4439 & 46.7 & 51.4 \\
I18 & 4464 & 294.1 & N/A \\
I57 & 4583 & 314.8 & N/A \\
I10 & 4754 & 303.3 & N/A \\
\hline
\end{tabular}

Figure 22. To detect signals, a $500 \mathrm{~s}$ window was stepped through the NVIAR data in $50 \mathrm{~s}$ iterations. For each iteration, estimates of (from top to bottom) trace velocity, azimuth of arrival, coherence, and planarity were computed from a least squares fit assuming plane wave arrivals. The windowing technique was applied to the NVIAR time series after band-pass filtering $(0.015-1 \mathrm{~Hz})$ followed by PureState filtering. The gray regions in all panels indicate the time intervals over which the Kasatochi signals are estimated to be detected at NVIAR based on known event times, known event durations, and estimated propagation times resulting from a wave propagation model.

by infrasound arrays several thousands of kilometers away. Out of the eight infrasound arrays considered in this study, seven were able to detect signals from Kasatochi while only three were able to detect signals from Okmok although seven of the eight arrays were closer to Okmok than Kasatochi. Noise from wind and from other noncoherent signals was probably not the cause of the nondetections since the Pure-State Filter greatly reduced the presence of all noncoherent signals prior to the application of any detection techniques.

[20] The primary reason for Kasatochi being detected by more infrasound arrays is probably the way in which the volcanoes ejected gases and tephra into the atmosphere. Okmok continuously released gases and tephra for extended periods of time on the order of $10 \mathrm{~h}$. In contrast, Kasatochi

Table 3. Great Circle Path Distances and Azimuths and Measured Azimuths to Kasatochi From Each Infrasound Array Sorted by Distance

\begin{tabular}{lccc}
\hline Array Name & $\begin{array}{c}\text { Distance to } \\
\text { Kasatochi (km) }\end{array}$ & $\begin{array}{c}\text { Azimuth to } \\
\text { Kasatochi (deg) }\end{array}$ & $\begin{array}{c}\text { Measured Azimuth to } \\
\text { Kasatochi (deg) }\end{array}$ \\
\hline I53 & 2104 & 241.2 & 242.8 \\
I30 & 3931 & 47.6 & 48.4 \\
I59 & 4002 & 339.5 & 340.9 \\
I56 & 4060 & 298.7 & 301.3 \\
NVIAR & 4591 & 308.7 & 309.9 \\
I18 & 4750 & 299.9 & 302.8 \\
I57 & 5067 & 312.6 & N/A \\
I10 & 5252 & 304.8 & 307.4 \\
\hline
\end{tabular}




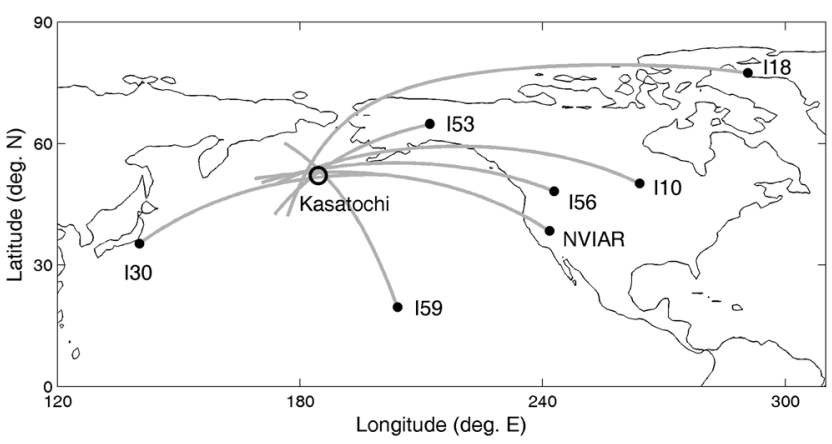

Figure 23. Simple back azimuth projections along the great circle paths from IMS stations results in an average location that is approximately $500 \mathrm{~km}$ west of Okmok and encompasses a region approximately $450 \mathrm{~km}$ wide.

released gases and tephra in shorter but stronger bursts ranging from 26 to $68 \mathrm{~min}$ in length with a cumulative duration of $3.4 \mathrm{~h}$. The two eruptions correspond roughly to different types of activity that have long been recognized in the volcanological literature. McBirney [1973] identified some eruptions as being analogous to fire hoses, in which the tephra particles are carried in a high-velocity but lowpressure gas stream. This case corresponds to Okmok, which is basaltic. The other type, represented by a cannon blast, is characterized by higher gas pressures and often shorter eruptions. This typically occurs with higher-viscosity magmas such as andesite or dacite because the high-viscosity retards the expansion of gases exsolving from rising magma so there is higher vapor pressure as the magma reaches the surface. This corresponds to Kasatochi which is andesitic (Waythomas et al., submitted manuscript, 2010). The characterization in terms of pressure agrees with the infrasound array observations of much higher pressures for the shortlived Kasatochi eruptions than the sustained but weaker Okmok eruption. Note that the Okmok eruption had a high component of phreatomagmatic activity (interaction with groundwater), which makes it more explosive than other basaltic activity [Larsen et al., 2009].

[21] For these volcanic events, there is a strong relationship between the distance of an infrasound array and the probability that it detects a signal, as might be expected. For

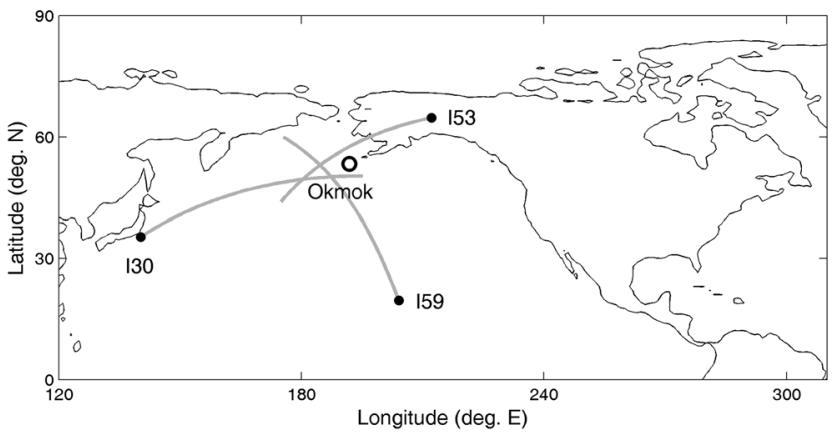

Figure 24. Simple back azimuth projections along the great circle paths from IMS stations results in an average location that is approximately $200 \mathrm{~km}$ west of Kasatochi and encompasses a region several hundred kilometers wide.
Table 4. Angles and Propagation Times of the Rays Originating From Okmok That Arrive at the Infrasound Arrays According to a Wave Propagation Model

\begin{tabular}{lccc}
\hline Array & $\begin{array}{c}\text { Angle From } \\
\text { Vertical }(\mathrm{deg})\end{array}$ & $\begin{array}{c}\text { Estimated } \\
\text { Propagation } \\
\text { Time }\left(10^{4} \mathrm{~s}\right)\end{array}$ & $\begin{array}{c}\text { Estimated } \\
\text { Propagation } \\
\text { Time (min) }\end{array}$ \\
\hline I10 & 37.7 & 1.8 & 300 \\
I18 & 32.9 & 1.3 & 210 \\
I18 & 87.4 & 1.5 & 250 \\
I18 & $37.6,79.9,80.1,90$ & 1.6 & 270 \\
I18 & 57.1 & 1.8 & 300 \\
I30 & 74.9 & 1.6 & 270 \\
I30 & 42 & 1.7 & 290 \\
I30 & 44.9 & 1.8 & 300 \\
I53 & 54.3 & 0.6 & 110 \\
I53 & 65.1 & 0.7 & 110 \\
I56 & 43.3 & 1.4 & 240 \\
I57 & 55.9 & 1.8 & 310 \\
I59 & 40.6 & 1.5 & 250 \\
I59 & 54.9 & 1.6 & 260 \\
NVIAR & 73.7 & 1.5 & 260 \\
\hline
\end{tabular}

example, the fifth explosion eruption of Kasatochi Volcano which occurred at 1206 UT was detected by the four closest infrasound arrays (I53, I30, I59, and I56), but not by the other four farther away (NVIAR, I18, I57, and I10). However, this relationship has exceptions. For example, the three arrays that detected signals from the event at Okmok (I53, I59, and I30) were not the three closest arrays, but rather the first, third, and fifth closest. As another example, the first explosive eruption of Kasatochi Volcano was detected by I10, the array farthest from the volcano at $4754 \mathrm{~km}$, but not by NVIAR or I57 which are closer at distances of 4097 and 4583 , respectively.

[22] The acoustic wave propagation model, in addition to providing estimates of propagation times, might also provide some insight as to why signal strength recorded at the arrays is not entirely dependent on distance from the source alone. Considering the previous example, the fact that the propagation model found seven rays that arrived at I10 and only one ray that arrived at I57 and NVIAR suggests that more of the signal's energy was able to arrive at I10 than at

Table 5. Angles and Propagation Times of the Rays Originating From Kasatochi That Arrive at the Infrasound Arrays According to a Wave Propagation Model

\begin{tabular}{lccc}
\hline Array & $\begin{array}{c}\text { Angle From } \\
\text { Vertical }(\mathrm{deg})\end{array}$ & $\begin{array}{c}\text { Estimated } \\
\text { Propagation } \\
\text { Time }\left(10^{4} \mathrm{~s}\right)\end{array}$ & $\begin{array}{c}\text { Estimated } \\
\text { Propagation } \\
\text { Time (min) }\end{array}$ \\
\hline I10 & 80.8 & 1.9 & 320 \\
I10 & $65.5,66.3,70.3$ & 2.0 & 330 \\
I10 & $41.1,41.2,49.7$ & 2.1 & 350 \\
I18 & $38.8,72.8$ & 1.8 & 300 \\
I18 & $49.4,56.0,56.2$ & 1.9 & 320 \\
I30 & 34.7 & 1.4 & 230 \\
I30 & $61.2,75.0$ & 1.5 & 250 \\
I53 & $50.3,52.9,53.063 .2,63.4,63.5$ & 0.8 & 140 \\
I53 & $42.7,48.6$ & 0.9 & 150 \\
I56 & $37.4,71.0,76.7$ & 1.5 & 250 \\
I56 & $38.1,39.5,61.6$ & 1.6 & 270 \\
I57 & 39.9 & 2.0 & 330 \\
I59 & 74.6 & 1.5 & 250 \\
I59 & $39.8,65.265 .6,65.7$ & 1.6 & 260 \\
I59 & $43.2,44.6,45.949 .5,49.7$ & 1.7 & 290 \\
NVIAR & 72.8 & 1.7 & 290 \\
\hline
\end{tabular}


I57 or NVIAR due to the temperature profile of the atmosphere at the time of the explosive eruptions. However, the acoustic wave propagation model did not take atmospheric winds into account. For a more complete analysis of the acoustic wave propagation associated with these volcanic events, the reader is directed to Fee et al. [2010].

[23] The estimated locations of the Okmok and Kasatochi events obtained from back azimuth projections differed from the actual locations of the volcanoes by approximately 500 and $200 \mathrm{~km}$, respectively, and had uncertainties on the order of several hundreds of kilometers. The error in the location estimate of Okmok is larger than that of Kasatochi simply because the deviations between the measured azimuths of arrival and actual azimuths to the volcanoes were larger for Okmok than for Kasatochi (Tables 2 and 3). These deviations in measured azimuths of arrival are likely due to the presence of atmospheric winds which can cause a signal's path to stray from that of the arc of a great circle that connects the source to the receiver. Possible ways to reduce errors in location estimates are to use an acoustic wave propagation model that incorporates the effects due to winds and to install infrasound arrays closer to the Aleutian Islands thereby reducing the path length over which winds might alter the propagation of the signal. The advantage to installing an infrasound array versus a signal sensor is that data recorded at an array would not only yield signal strength and time of signal arrival as the signal sensor would, but the array data can also provide azimuth of signal arrival and are more useful for signal detection since signals that are coherent across all time series can be sought out by filters such as the Pure-State Filter.

[24] The infrasound array data are complementary to local seismic network data such as those provided by AVO. For the Okmok and Kasatochi eruptions, AVO scientists notified the infrasound group that the eruptions had occurred and gave the onset times to within a few minutes. This enabled focused efforts to identify the infrasound signals knowing the estimated propagation time and azimuth in advance. From the perspective of monitoring, the infrasound array data are useful because they are independent, and they provide additional constraints on the relative sizes of different events. The long distances of 1700 and $2100 \mathrm{~km}$ to I53 and the long travel times of 110 and 130 min mean that the infrasound data are less useful for rapid notification. Another way the infrasound array data were useful was to help distinguish between tremor episodes that appeared similar to the eruption tremor in seismic data (Kasatochi episodes at 1915 and 2108 UT) but for which no infrasound signals were detected, hence confirming that these tremor episodes had a different source process.

[25] The two eruptions considered in this paper were quite different, and thus provided a good comparison of the ability of infrasound array data to characterize the activity. The Okmok eruption was a sustained eruption lasting about $10 \mathrm{~h}$ (fire hose analogy), with likely high-velocity but lowpressure ejection at the source vent. This showed up in the array data as long-lasting but low-amplitude signals. In contrast, the Kasatochi eruptions were a series of five short but strong blasts lasting 26 to $68 \mathrm{~min}$ each (cannon analogy). These represented higher pressures and shorter eruptions at the vent. The corresponding infrasound array data showed stronger signals with shorter durations, and these were recorded at greater distances. The array data clearly showed these fundamental differences despite the great distances involved. The infrasound array data combined with local seismic, local infrasound, and remote sensing data provide a powerful suite of tools to determine eruption characteristics.

[26] Acknowledgments. This work represents one aspect of the research supported by the Geophysical Institute, UAF. Data from arrays I10, I18, and I30 were provided by the IMS program. Data from the NVIAR array were provided by the Southern Methodist University. The authors would like to express their gratitude to Douglas Drob of the U.S. Naval Research Laboratory (NRL) for his assistance with utilizing the NRL-G2S Atmospheric Data System. NASA Goddard Space Flight Center, Global Modeling and Assimilation Office (GMAO), and the NOAA National Centers for Environmental Prediction (NCEP) provided the global numerical weather prediction analysis fields that went into the hybrid G2S atmospheric specifications.

\section{References}

Aki, K., and R. Koyanagi (1981), Deep volcanic tremor and magma ascent mechanism under Kilaueu, Hawaii, J. Geophys. Res., 86(B8), 70957109, doi:10.1029/JB086iB08p07095.

Dixon, J. P., S. D. Stihler, J. A. Power, G. Tytgat, S. Estes, and S. R. McNutt (2006), Catalog of earthquake hypocenters at Alaskan volcanoes: January 1 through December 31, 2005, U.S. Geol. Surv. Open File Rep., $1264,78 \mathrm{pp}$.

Drob, D. P., J. M. Picone, and M. Garcés (2003), Global morphology of infrasound propagation, J. Geophys. Res., 108(D21), 4680, doi:10.1029/2002JD003307.

Fee, D., A. Steffke, and M. Garcés (2010), Characterization of the 2008 Kasatochi and Okmok eruptions using remote infrasound arrays, J. Geophys. Res., 115, D00L10, doi:10.1029/2009JD013621.

Fehler, M. (1983), Observations of volcanic tremor at Mount St. Helens Volcano, J. Geophys. Res., 88(B4), 3476-3484, doi:10.1029/ JB088iB04p03476.

Larsen, J., C. Neal, P. Webley, J. Freymueller, M. Haney, S. McNutt, D. Schneider, S. Prejean, J. Schaeffer, and R. Wessels (2009), Eruption of Alaskan volcano breaks historic pattern, Eos Trans. AGU, 90, 173-174, doi:10.1029/2009EO200001.

McBirney, A. R. (1973), Factors governing the intensity of explosive andesitic eruptions, Bull. Volcanol., 37, 443-453, doi:10.1007/ BF02597641.

McNutt, S. R., T. Miller, and J. J. Taber (1991), Pavlof Volcano: Seismological and geological evidence of increased explosivity during the 1986 eruptions, Bull. Volcanol., 53, 86-98, doi:10.1007/BF00265414.

Olson, J. V. (2004), The application of the Pure-State Filter to infrasound array data, Inframatics, 7, 15-21.

Petersen, T., and S. R. McNutt (2007), Seismo-acoustic signals associated with degassing explosions recorded at Shishaldin Volcano, Alaska, 2003-2004, Bull. Volcanol., 69, 527-536, doi:10.1007/s00445-0060088-z.

Szuberla, C. A. L., and J. V. Olson (2004), Uncertainties associated with parameter estimation in atmospheric infrasound arrays, J. Acoust. Soc. Am., 115, 253-258, doi:10.1121/1.1635407.

Thompson, G., S. R. McNutt, and G. Tytgat (2002), Three distinct regimes of volcanic tremor associated with eruptions of Shishaldin Volcano, Alaska, 1999, Bull. Volcanol., 64, 535-547, doi:10.1007/s00445-0020228-z.

K. M. Arnoult, D. Fee, J. V. Olson, and C. A. L. Szuberla, Wilson Infrasound Observatories, Geophysical Institute, University of Alaska Fairbanks, 903 Koyukuk Dr., PO Box 757320, Fairbanks, AL 99775, USA. (kma@gi.alaska.edu)

M. A. Garcés, Infrasound Laboratory, Hawaii Institute of Geophysics and Planetology, SOEST, University of Hawaii at Manoa, 73-4460 Queen Kaahumanu Hwy., 119, Honolulu, HI 96740-2638, USA.

M. A. H. Hedlin, Laboratory for Atmospheric Acoustics, Institute of Geophysics and Planetary Physics, University of California, San Diego, 9500 Gilman Dr., MC 0225, La Jolla, CA 92093-0225, USA.

S. R. McNutt, Alaska Volcano Observatory, Geophysical Institute, University of Alaska Fairbanks, 903 Koyukuk Dr., PO Box 757320, Fairbanks, AL 99775, USA. 